\title{
Forro ecológico de resíduos agroindustriais para galpões avícolas
}

\author{
Ecological lining of agro industrial waste for poultry houses
}

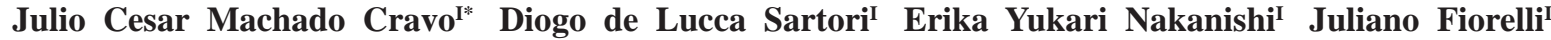 \\ Julio Cesar de Carvalho Balieiro ${ }^{I}$ Wilson Nunes dos Santos ${ }^{I I}$
}

RESUMO

A avicultura brasileira é uma atividade econômica com expressiva participação no agronegócio brasileiro, porém o setor se depara com desafios, entre esses, destaca-se o estresse térmico dos animais provocado pelas variações climáticas. Dentro desse contexto, este trabalho teve como objetivo estudar as propriedades térmicas de um forro ecológico de baixa densidade a base de partículas de resíduos agroindustriais (casca de amendoim e fibra de coco verde) aglutinadas com resina poliuretana bicomponente à base de óleo de mamona e avaliar seu desempenho quando aplicado como forro em galpões avícolas. Os resultados obtidos demonstram a eficiência do material quando aplicado como forro em aviários.

Palavras-chave: instalações zootécnicas, avicultura, isolamento térmico.

\section{ABSTRACT}

The Brazilian poultry industry is one the activities relevant to the agribusiness, but the industry is faced with challenges such as heat stress, which is influenced by climate. The production of eco-lining is an alternative that adds value to waste and helps to solve the problem of thermal control in poultry houses. This research aimed to study thermal properties of an ecological liner low density particle-based on agribusiness residues (peanut hulls and coconut fiber) agglutinated with bicomponent polyurethane resin based on castor oil and evaluate its performance when applied as lining in poultry houses. The results show that the material has the potential to be used as lining in poultry broiler.

Key words: husbandry facilities, poultry, thermal insulation.

\section{INTRODUÇÃO}

O agronegócio é o setor da economia que vem contribuindo significativamente com o crescimento do País e é um dos responsáveis pelo superávit na balança comercial brasileira. Segundo os dados do MAPA (2012), esse setor teve participação de 36,94\% nas exportações brasileiras em 2011. Considerando o segmento cárneo, a carne de frango foi o produto mais exportado pelo Brasil, com aproximadamente 3707 mil toneladas, resultando em 7497 milhões de dólares.

Apesar do cenário ser favorável para avicultura brasileira nos próximos anos, é necessário que as integradoras e produtores independentes aprimorem seus galpões avícolas, uma vez que o sucesso dessa atividade depende do micro clima interno das instalações, uma vez que as aves são sensíveis à variação de temperatura (CRAVO et al., 2012).

OLIVEIRA et al. (2006) estudaram a influência da temperatura no desempenho de frangos de corte. Os autores constataram resultados zootécnicos inferiores, para aves criadas em altas temperaturas $\left(32^{\circ} \mathrm{C}\right)$. Além disso, os autores diagnosticaram redução no peso dos órgãos, que, segundo os pesquisadores, está atrelado ao ajuste fisiológico da ave, com intuito de produzir menos calor corporal.

\footnotetext{
ICentro de Pesquisa Construções e Ambiência, Faculdade de Zootecnia e Engenharia de Alimentos, Universidade de São Paulo (USP), 13635-900, Pirassununga, SP, Brasil. E-mail: juliomachadomachado@hotmail.com. *Autor para correspondência.

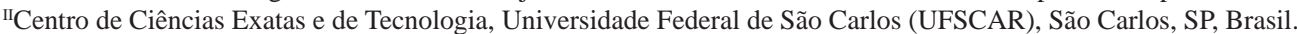


Considerando queduranteo cicloprodutivo, as aves ficam confinadas por aproximadamente 42 dias, torna-se necessária cautela e atenção durante a edificação de uma instalação avícola para frangos de corte, pois, segundo BAÊTA \& SOUZA (2010), os materiais podem afetar de forma significativa o ambiente interno da instalação, resultando em pronunciado efeito sobre o conforto das aves.

Dentre esses materiais, aqueles utilizados nas coberturas são os que mais influenciam no micro clima interno dos galpões avícolas, pois, segundo NÄÄS et al. (2001), o telhado é o elemento construtivo que exerce maior influência no controle da radiação solar. No entanto, nem sempre a cobertura é suficiente para proporcionar ambiente confortável para as aves, tornando-se necessária a adição de novas técnicas, como a associação de forro sob a cobertura (TINÔCO, 2001).

Segundo TINÔCO (2001), o poliuretano, eucatex, lã de vidro entre outros são os principais materiais utilizados como materiais isolantes. No entanto, LIANG \& HO (2007) demonstraram que os materiais isolantes inorgânicos (fibra de vidro, lã de rocha, espuma de polietileno e espuma de poliuretano) apresentaram altos índices de toxidades para os humanos, os quais podem ser prejudiciais para as aves.

Baseado nessa premissa, sugere-se a importância de buscar materiais isolantes que possam ser menos agressivos ao ambiente e aos animais. Nesse âmbito, CAMERINI et al. (2009) avaliaram a influência do forro a base de resíduo EVA (EtilenoAcetato de Vinila) em modelos reduzidos de instalações agropecuárias. Segundo os autores, o forro possibilitou redução nos valores dos índices térmicos.

Considerando que a agroindústria brasileira gera quantidades significativas de resíduos, sendo esses utilizados, em sua maioria, para geração de energia, a produção de forro ecológico a base de partículas de fibra da casca do coco verde e de casca de amendoim pode ser uma alternativa para agregar valor aos resíduos e, ao mesmo tempo, contribuir com a redução da temperatura interna de aviários.

Dentro desse contexto, o presente trabalho teve como objetivo avaliar o desempenho térmico de um Forro Ecológico de baixa densidade $\left(0,5 \mathrm{~g} \mathrm{~cm}^{-3}\right)$, a base de partículas de resíduos agroindustriais (casca de amendoim e fibra de coco) aglutinadas com resina poliuretana a base de óleo de mamona, visando sua aplicação em galpões avícolas.

\section{MATERIAL E MÉTODOS}

Fabricação do forro ecológico

O processo de fabricação do forro ecológico seguiu os seguintes procedimentos: os resíduos foram dispostos em uma estufa, modelo MA035, com temperatura de $60^{\circ} \mathrm{C}$, durante o período de 24 horas; após a secagem, o material foi picado em um moinho de faca (MA683/3) com malha de 8mm e pesados em uma balança eletrônica (AY220) para averiguar a massa total (50\% de casca de amendoim e $50 \%$ de fibra de coco verde) necessária para produzir os Forros Ecológicos, com densidades de $0,5 \mathrm{~g} \mathrm{~cm}^{-3}$ (AMERICAN NATIONAL STANDARD PARTICLEBOARD - ANSI A208.1 - 1999).

Posteriormente, as partículas foram levadas a um misturador planetário (MT120) quando foi adicionado adesivo poliuretano a base de óleo de mamona, com proporção de $15 \%$ do peso seco da matéria prima. Finalizada a mistura, o material foi acondicionado em um molde formador de painel $(40 \mathrm{~cm} \times 40 \mathrm{~cm} x 2 \mathrm{~cm})$ e remetidas para uma prensa termo-hidráulica, com temperatura média de $100^{\circ} \mathrm{C}$, por aproximadamente 10 minutos de prensagem, com pressão média de $5 \mathrm{MPa}$. Após a saída da prensa, os painéis ficaram empilhados por 72 horas, período em que ocorreu a continuação do processo de cura da resina.

\section{Condutividade térmica}

O método utilizado para averiguar a condutividade térmica do material foi o "Método do Fio Quente Paralelo”. Esse ensaio foi realizado no laboratório de Engenharia de Materiais da Universidade Federal de São Carlos.

$\mathrm{Na}$ parte superior de um dos corpos de prova, foram feitos dois sulcos, com objetivo de inserir o fio quente (resistência) e o termopar. A condutividade térmica do material foi obtida pela aplicação de uma corrente contínua ao fio quente e, uma vez por segundo, verificou-se o gradiente com o auxílio do termopar. No final do experimento, o software forneceu a condutividade térmica.

Resistência térmica, transmitância térmica e fator solar Com o dado de condutividade térmica do Forro Ecológico, foi calculada a resistência e a transmitância térmica do material, adotando as equações da Normativa Desempenho Térmico de Edificações (02:135.07-001/2).

Com base nessas duas propriedades térmicas, foi determinado o Fator Solar (FS $)$ no período de verão, maior tendência de estresse térmico, simulando duas instalações avícolas, a saber: a) com cobertura de fibrocimento (densidade: $1,7 \mathrm{~g} \mathrm{~cm}^{-3}$; espessura: 0,008cm; condutividade: $0,65 \mathrm{~W} \mathrm{mK}^{-1}$ ) pintada de branco (absortância: 0,3); e b) com cobertura de fibrocimento pintada de branco e Forro Ecológico (densidade: 0,5g $\mathrm{cm}^{-3}$; espessura: $2 \mathrm{~cm}$ ), para o período de verão. Foram adotadas as equações da Normativa Desempenho Térmico de Edificações (02:135.07-001/2). 
A fim de averiguar a quantidade de radiação solar que seria transmitida para o interior desses aviários (Sem Forro e Com Forro), nos horários das 08h00min, 10h00min, 12h00min, 14h00min, $16 \mathrm{~h} 00 \mathrm{~min}$ e $18 \mathrm{~h} 00 \mathrm{~min}$, utilizaram-se os $\mathrm{FS}_{0}$ e os dados de radiação solar coletados por uma Estação Meteorológica (Vantage Pro2), localizada na região Sudeste do Brasil, no centro Norte do Estado de São Paulo. Foram selecionados dados do mês de Janeiro de 2012, por ser a época do ano com incidência de maiores temperaturas.

Com o propósito de investigar se existiria diferença estatística entre a quantidade de radiação solar que seria transmitida aos aviários nos respectivos horários aventados, foi elaborado um experimento de acordo com o delineamento em blocos casualizados (DBC), em que os tratamentos foram organizados em esquema fatorial $2 \mathrm{X} 5$, e os fatores estudados corresponderam a Ambiente Térmico e Horas. O fator Ambiente Térmico consistiu de dois níveis (Sem Forro e Com Forro) e o fator Horas compreendeu a seis níveis $(08 \mathrm{~h} 00 \mathrm{~min}, 10 \mathrm{~h} 00 \mathrm{~min}, 12 \mathrm{~h} 00 \mathrm{~min}$, $14 \mathrm{~h} 00 \mathrm{~min}, 16 \mathrm{~h} 00 \mathrm{~min}$ e $18 \mathrm{~h} 00 \mathrm{~min}$ ), totalizando doze tratamentos. As repetições de cada tratamento foram consideradas os dias do mês de janeiro, ou seja, cada tratamento dispunha de 31 repetições.

Os dados qualitativos (fator - ambiente térmico) foram analisados por meio do teste $\mathrm{F}$ quando a ANOVA foi significativa, sendo ambos testados a $\mathrm{P}<0$,05. Já os dados quantitativos (fator - horas) foram analisados por meio da regressão. O software utilizado para interpretação dos dados foi o SISVAR versão 5.3.

\section{RESULTADOS E DISCUSSÃO}

Condutividade térmica

O ensaio de condutividade térmica efetuado pela técnica de fio quente paralela revelou que o Forro Ecológico apresenta condutividade térmica de 0,29W mK $\mathrm{m}^{-1}$. Esse valor é superior aos materiais isolantes comerciais: lã de rocha $\left(0,045 \mathrm{~W} \mathrm{mK}^{-1}\right)$, lã de vidro $\left(0,045 \mathrm{~W} \mathrm{mK}^{-1}\right) \mathrm{e}$ poliestireno expandido $\left(0,040 \mathrm{~W} \mathrm{mK}^{-1}\right)(\mathrm{DESEMPENHO}$ TÉRMICO de EDIFICAÇÕES, 2003).

A diferença dessa propriedade pode estar relacionada com a quantidade de ar presente nos materiais isolantes, que, segundo ZHOU et al. (2010), é o condutor mais pobre. A baixa condutividade térmica do poliestireno expandido pode ser devido à quantidade de ar no interior do material, pois, de acordo com PAPADOPOULOS (2005), esse isolante contém 98-98,5\% de ar.

Embora o Forro Ecológico tenha exibido maior condutividade térmica que os materiais isolantes, esse material tem a vantagem de ser sustentável, o que contribui para benefícios ambientais, tais como o aquecimento global, uma vez que, segundo GULER et al. (2007), os resíduos agroindustriais são queimados no campo.

Resistência térmica, transmitância térmica e fator solar Com base no valor da condutividade térmica, foi determinada a resistência e transmitância térmica do Forro Ecológico, cujos valores são: $\mathrm{R}=0,0673174 \mathrm{~m}^{2} \mathrm{KW}^{-1}$ e $\mathrm{U}=14,8549999 \mathrm{Wm}^{2} \mathrm{~K}^{-1}$.

Mediante esses valores, foi calculado o $\mathrm{FS}_{\mathrm{o}}$, simulando dois aviários, sendo um com cobertura de fibrocimento pintada de branco e o outro com a mesma cobertura de fibrocimento e Forro Ecológico. O FS no aviário com cobertura de fibrocimento pintada de branco foi de 5,49\%, enquanto que o $\mathrm{FS}_{\mathrm{o}}$ para o aviário com Forro Ecológico foi de 2,40\%. Isso demonstra que, de $100 \%$ da radiação solar incidente sobre a cobertura, somente 2,40\% da radiação passaria para o interior do aviário dotado com Forro Ecológico.

Para quantidade de radiação solar que seria transmitida para o interior dos aviários supracitados, referentes aos horários das 08h00min, 10h00min, 12h00min, 14h00min, 16h00min e 18h00min, a análise da ANOVA revelou interação significativa $(\mathrm{P}<0,05)$ entre os fatores: Ambiente Térmico versus Horas. Dessa forma, foram geradas equações de regressão para cada Ambiente Térmico (Sem Forro e Com Forro), descritas na tabela 1, com o propósito de estimar o comportamento da radiação solar que seria transmitida para interior desses aviários. Notase que as equações apresentaram altos coeficientes de determinação $\left(\mathrm{R}^{2}\right)$, indicando que o modelo quadrático explica o fenômeno estudado.

Mediante as equações de regressão, foi sintetizado o gráfico representado na figura 1. Observa-

Tabela 1 - Equações de Regressão dos ambientes e os respectivos coeficientes de determinação.

\begin{tabular}{lll}
\hline Ambientes & \multicolumn{1}{c}{ Equações ajustadas } & $\mathrm{R}^{2}$ \\
\hline Com Forro & $\mathrm{Y}=-87,789533^{*}+16,092934 * \mathrm{H}-0,603357 * \mathrm{H}^{2}$ & $95,20 \%$ \\
Sem Forro & $\mathrm{Y}=-200,813362 *+36,811822 * \mathrm{H}-1,380155 * \mathrm{H}^{2}$ & $95 \%$ \\
\hline
\end{tabular}

*Significativo a $\mathrm{P}<0,05$. 


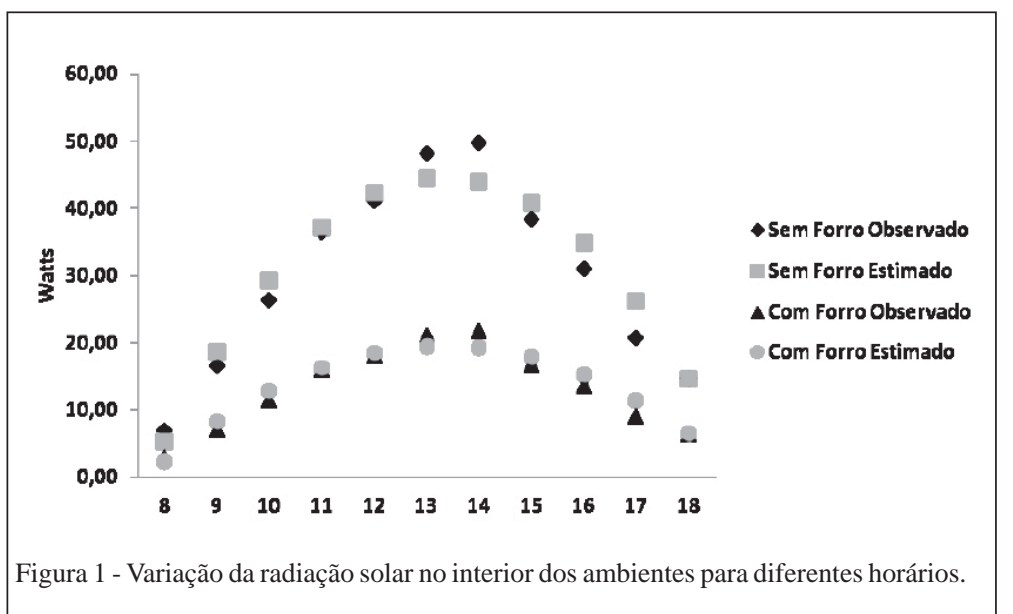

se que o ambiente com forro exibiria significativamente menores valores de radiação para todos os horários avaliados, ou seja, menores quantidades de radiação solar seriam transmitidas para o interior desse aviário.

Esse comportamento tem relação com a presença de camada de ar e Forro Ecológico na instalação. Além da camada de ar atuar como isolante entre a cobertura e o Forro Ecológico, o próprio forro também atuaria como camada para reduzir a transferência de radiação para o interior da instalação, pois, de acordo com TANGJUANK \& KUMFU (2011), os espaços preenchidos por ar servem como centros de dispersão fônons, sendo que a transferência do fluxo de calor é menor, devido à baixa condutividade térmica do ar.

Para TINÔCO (2001), a colocação de forro isolante sob os telhados proporciona a criação de uma camada de ar (baixa condutividade térmica) entre o forro e a cobertura, resultando em alta resistência térmica para o sistema (cobertura, ar e forro) e consequentemente a transmissão de radiação solar. Segundo a autora, os materiais isolantes são porosos, cuja elevada resistência térmica se baseia na condutividade térmica do ar contido em seus vazios. Assim, quanto menor a densidade do material, maior o número de poros, menor a condutividade térmica e, consequentemente, maior o poder de isolamento.

Segundo BAÊTA \& SOUZA(2010), sempre que um corpo recebe energia radiante, há acréscimo na sua carga interna, por essa razão, sua temperatura aumenta; da mesma forma, no processo inverso, há redução da temperatura do corpo. De acordo com os autores, a radiação solar incidente é um fator que afeta a temperatura interna das instalações, influenciando o conforto térmico. Com base nessa informação, inferese que a instalação sem forro apresentaria maior temperatura interna. No entanto, seriam necessários estudos em instalações avícolas para averiguar se as temperaturas seriam confortáveis para frangos de corte.

Derivando as equações dos ambientes (Tabela 1), constatou-se que o horário das 13h33min é o período do dia em que maior quantidade de radiação seria transmitida para o interior dos aviários, sendo necessário cautela e atenção para os animais, durante esse período do dia.

A tabela 2 sumariza a análise do Teste $\mathrm{F}$ para os tratamentos estudados. É possível identificar, para todos os horários estudados, que a instalação com Forro Ecológico apresentaria transmissão de radiação solar média menor e diferente $(\mathrm{P}<0,05)$, em comparação com a instalação sem forro, demonstrando a eficiência do Forro Ecológico.

Proposta de aplicação do forro ecológico para aviários

As análises das propriedades térmicas demonstram que o Forro Ecológico apresenta potencial de aplicação em galpões de frango de corte. Dessa forma, elaborou-se a figura 2, a qual representa a parte do telhado com Forro Ecológico em uma

Tabela 2 - Valores médios experimentais da radiação solar transmitida.

\begin{tabular}{llllllll}
\hline Ambientes térmicos/horas & \multicolumn{1}{c}{8} & 10 & 12 & 14 & 16 & 18 & Média \\
\hline Com forro & $3,02 \mathrm{~A}$ & $11,47 \mathrm{~A}$ & $17,98 \mathrm{~A}$ & $21,72 \mathrm{~A}$ & $13,54 \mathrm{~A}$ & $6,71 \mathrm{~A}$ & 12,4 \\
Sem forro & $6,91 \mathrm{~B}$ & $26,26 \mathrm{~B}$ & $41,12 \mathrm{~B}$ & $49,70 \mathrm{~B}$ & $30,97 \mathrm{~B}$ & $15,36 \mathrm{~B}$ & 28,38 \\
Média & 4,96 & 18,86 & 29,55 & 35,71 & 22,25 & 11,03 \\
\hline
\end{tabular}

Médias seguidas por letras maiúscula na coluna não diferem significativamente a 5\% pelo Teste F.

Ciência Rural, v.44, n.8, ago, 2014. 


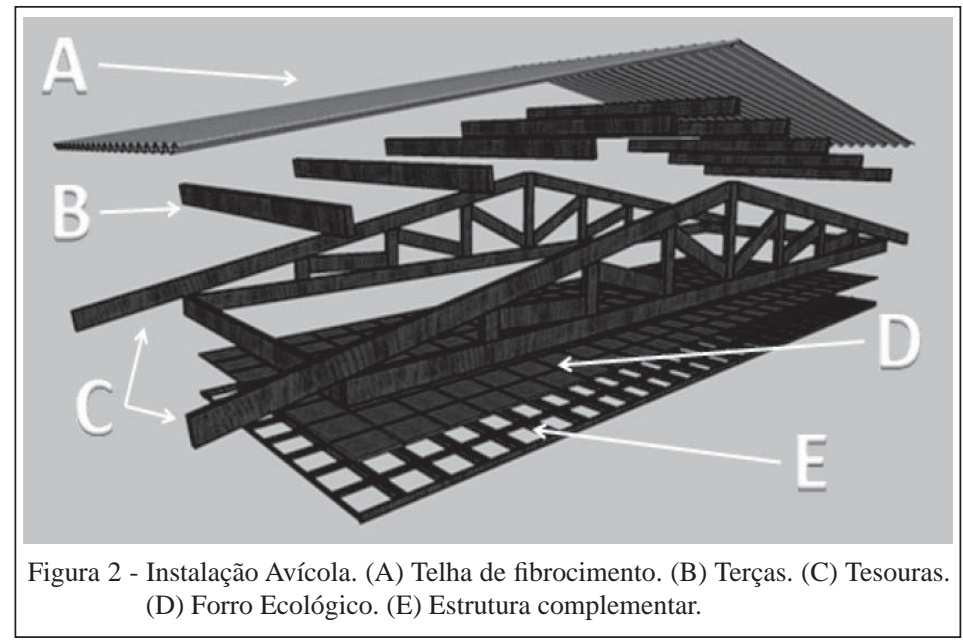

instalação avícola. Observa-se que, para execução do Forro Ecológico, é necessário a construção de uma estrutura de madeira complementar, posicionada abaixo do nível das tesouras.

\section{CONCLUSÃO}

Com base no exposto, conclui-se que o Forro Ecológico a base de casca de amendoim e fibra da casca de coco verde apresentou condutividade térmica superior aos materiais comerciais. No entanto, a presença do Forro Ecológico em uma instalação avícola coberta com telha de fibrocimento reduziu significativamente o FS, em comparação à mesma instalação sem forro, demonstrando ser um material com potencial para uso em galpões avícolas.

\section{AGRADECIMENTOS}

Os autores agradecem à Fundação de Amparo à Pesquisa do Estado de São Paulo (FAPESP), pelo apoio financeiro concedido para realização dessa pesquisa e do mestrado de Julio Cesar Machado Cravo ( No Processo 2011/03707-2).

\section{REFERÊNCIAS}

ABNT 02:135.07-001/2. Desempenho térmico de edificações parte 2: métodos de cálculo da transmitância térmica, capacidade térmica, do atraso térmico e do fator solar de elementos e componentes de edificações. Rio de Janeiro, 2003. 28p.

ANSI A208.1. American National Standard Particleboard. USA, 1999. 13p.

BAÊTA, F.C.; SOUZA, C.F. Ambiência em edificações rurais conforto térmico. Viçosa: UFV, 2010. 269p.

CAMERINI, N.L. et al. Análise de variáveis ambientais em modelos reduzidos de instalações agropecuárias com forro de resíduo de EVA. Revista Eletrônica de Materiais e Processos, v.4, n.2, p.40-47, 2009. Disponível em: <http://www.dema.ufcg. edu.br/revista/index.php/REMAP/article/viewFile/115/116>. Acesso em: 15 dez. 2011.

CRAVO, J.C.M et al. Aplicação de painéis particulados de baixa densidade à base de resíduos agroindustriais como forro para galpões avícolas, Brasília, DF, 2012. In: REUNIÃO ANUAL DA SOCIEDADE BRASILEIRA DE ZOOTECNIA, 49., 2012, Brasília, DF. Anais... Brasília: SBZ, 2012. CD.

GULER, C. et al. The manufacture of particleboards using mixture of peanut (Arachis hypoqaea) and European Black pine (Pinus nigra Arnold) wood chips. Bioressource Technology, v.99, p.2893-2897, 2007. Disponível em: <http://www.sciencedirect. com/science/article/pii/S0960852407004865>. Acesso em: 10 ago. 2011.

LIANG, H.H.; HO, M.C. Toxicity characteristics of commercially manufactured insulation materials for building applications in Taiwan. Construction and Building Materials, v.21, n.1, p.1254-1261, 2007. Disponível em: <http://www.sciencedirect. com/science/article/pii/S0950061806001851>. Acesso em: 10 jan. 2012.

MINISTÉRIO DA AGRICULTURA, PECUARIA E ABASTECIMENTO (MAPA). Estatística e dados básicos de economia agrícola. Brasília: Departamento de Economia Agrícola, 2012. 46p.

NÄÄS, I.A. et al. Avaliação térmica de telhas de composição de celulose e betumem, pintadas de branco, em modelos aviários com escala reduzida. Revista de Engenharia Agrícola, v.21, n.2, p.121-126, 2001.

OLIVEIRA, G.A. et al. Efeitos da temperatura ambiente sobre o desempenho e as características de carcaça de frangos de corte dos 22 aos 42 dias. Revista Brasileira de Zootecnia, v.35, n.4, p.1398-1405, 2006. Disponível em: <http://www.scielo.br/pdf/ rbz/v35n4/20.pdf>. Acesso em: fev. 2011.

PAPADOPOULOS, A.M. State of the art in thermal insulation materials and aims for future developments. Energy and 
Buildings, v.37, p.77-86, 2005. Disponível em: <http://www. sciencedirect.com/science/article/pii/S0378778804001641>. Acesso em: ago. 2011.

TINÔCO, I.F.F. Avicultura industrial: novos conceitos de materiais, concepção e técnicas construtivas disponíveis para galpões avícolas brasileiros. Revista Brasileira de Ciência Avícola, v.3, n.1, p.01-26, 2001. Disponível em: <http://www.scielo. br/scielo.php?pid=S1516-635X2001000100001\&script=sci arttext>. Acesso em: 20 jan. 2012. doi:10.1590/S1516635X2001000100001.
TANGJUANK, S.; KUMFU, S. Particle boards from papyrus fibers as thermal insulation. Journal of Applied Sciences, v.11, n.14, p.2640-2645, 2011. Disponível em: <http://scialert.net/ qredirect.php?doi=jas.2011.2640.2645\&linkid=pdf $>$. Acesso em: 15 jan. 2012. doi:10.3923/jas.2011.2640.2645.

ZHOU, X.Y. et al. An environment-friendly thermal insulation material from cotton stalk fibers. Energy and Buildings, v.42, p.1070-1074, 2010. Disponível em: <http://www.sciencedirect. com/science/article/pii/S0378778810000277>. Acesso em: 10 dez. 2011. 